Article

\title{
Investigation of Informal Settlement Indicators in a Densely Populated Area Using Very High Spatial Resolution Satellite Imagery
}

\author{
Naledzani Mudau ${ }^{1,2, *}$ and Paidamwoyo Mhangara ${ }^{1}$ \\ 1 School of Geography, Archeological \& Evironmental Studies, Faculty of Science, University of \\ the Witwatersrand, Johannesburg 2000, South Africa; paida.mhangara@wits.ac.za \\ 2 South African National Space Agency, Pretoria 0184, South Africa \\ * Correspondence: 1569579@students.wits.ac.za or NMudau@sansa.org.za
}

Citation: Mudau, N.; Mhangara, P. Investigation of Informal Settlement Indicators in a Densely Populated Area Using Very High Spatial Resolution Satellite Imagery. Sustainability 2021, 13, 4735. https://doi.org/10.3390/su13094735

Academic Editor: Miguel Amado

Received: 24 February 2021

Accepted: 8 April 2021

Published: 23 April 2021

Publisher's Note: MDPI stays neutral with regard to jurisdictional claims in published maps and institutional affiliations.

Copyright: () 2021 by the authors. Licensee MDPI, Basel, Switzerland. This article is an open access article distributed under the terms and conditions of the Creative Commons Attribution (CC BY) license (https:// creativecommons.org/licenses/by/ $4.0 /)$.

\begin{abstract}
Automation of informal settlements detection using satellite imagery remains a challenging task in urban remote sensing. This is due to the fact that informal settlements vary in shape, size and spatial arrangement from one region to the other in some cases within a city. This paper investigated the methodology to detect informal settlements in a densely populated township by assessing informal settlement indicators observed from very high spatial resolution satellite imagery. We assessed twelve informal settlement indicators to determine the most effective indicators to distinguish between informal and informal classes. These indicators included the spectral indices first and second-order statistical measurements. In addition to the commonly used informal settlement indicators, we assessed the effectiveness of built-up area and iron cover. The GLCM textural measures performed poorly in separating informal and formal settlements compared to first-order statistics measurement and spectral indices. The built-up area index, coastal blue index and the first-order statistics mean measurements produced higher separability distance of informal and formal settlements. The iron index performed better in separating the two settlement types than the commonly used GLCM measure and NDVI. The proposed ruleset that uses the three features with the highest separability distance achieved producer and user accuracies of informal settlements of $95 \%$ and $82 \%$, respectively. The results of this study will contribute towards developing methodologies to automatically detect informal settlements.
\end{abstract}

Keywords: informal settlements; worldview; South Africa; Mamelodi; GLCM; BAI; iron index; coastal blue index; city of Tshwane

\section{Introduction}

More than $58 \%$ of the world population lived in urban areas in 2018, and the number is expected to increase to $75 \%$ in 2050 [1]. Unfortunately, urbanization in developing countries is not always linked to economic development [2] and may lead to an increase in the number of people without access to basic infrastructure and the proliferation of informal settlements or slums. Informal settlements usually lack access to basic services and are not included during the planning of the cities, leading to these areas having poor living standards and being a source of social ills, such as crime and drug abuse [3]. With future urbanization expected to take place in towns and cities of developing countries, the number of people living in slums is expected to double, i.e., more than 3 billion by 2050 [4]. While most developing countries are already struggling with the effects of rapid urbanization, future urbanization may result in increased development of informal settlements, poverty and inequality. Information on the extent, population or condition of the informal settlement of informal settlements is not always available, which results in these areas not included in the government plans and policies [5]. This calls for a need to develop new methodologies to generate data and information to support the management of informal settlements. 
The common source of information on informal settlements in many countries is census data. Census is usually done every five to ten years period, leading to data gap challenges [6,7]. In addition, information collected during the census contains mainly headcount information and lacks the spatial dimension on the informal settlement [8]. Information on the population and condition of informal settlements is also collected through surveys to support specific projects. These projects may vary from informal upgrade programs to the provision of services by non-governmental institutions. This leads to spatial and temporal gaps in informal settlement data as the procedures used to survey informal settlements are not always published [9]. In addition, data collection using surveys is a time-consuming and resource-intensive exercise that governments are unable to maintain due to prohibitive costs associated with these data collection methods [10].

Remote sensing provides an opportunity to map and characterize human settlements based on their morphology, allowing for the cost-effective data collection on informal settlements [11]. The use of remote sensing data can independently map a countrywide to a city-wide location and condition of informal settlements. Remote sensing technologies that have been investigated in the literature for informal settlements mapping include aerial photography [12,13], unmanned aerial vehicles [14] and satellite imagery [8,15-19].

Methodologies used in mapping informal settlements from remote sensing data include visual image interpretation, traditional pixel-based classification, Object-based image analysis (OBIA) and machine learning techniques. The visual image interpretation method is usually applied to very high spatial resolution satellite imagery. Even though this methodology is time-consuming and resource-intensive, it is still commonly used as it produces higher accurate results when performed by experienced technicians than automated methodology [20].

The detection of settlement types using spectral characteristics alone is not possible. This is due to varying physical characteristics of informal settlements [15,21], roof materials of the dwelling structures within informal settlements [22,23] and development stages $[16,24]$. Many studies in the literature used object and settlement characteristics to detect informal settlements from satellite imagery with varying accuracy based on the informal settlement indicator and geographic area. To solve the problem associated with the detection of informal settlements using only spectral characteristics, generic slum ontology (GSO) was developed to assist with the detection and mapping of informal settlements from remotely sensed data across the globe. The GSO is based on the built morphology of informal settlements at three spatial levels, i.e., environment, settlement and object [8]. Building density remains the most explored settlement indicator that produces high accuracy compared to other indicators [8,16,18,25-27]. The use of gray-level co-occurrence matrix (GLCM) textural statistics has been investigated with varying accuracies depending on the morphology of the informal settlements and surrounding settlements [25]. In some cases, GLCM textural analysis fails to detect informal settlements from the built-up area $[26,27]$.

Even though several studies have focused on detecting informal settlements in different geographic areas, an automated methodology for informal settlement mapping from remotely sensed data still does not exist. In addition, varying accuracies are achieved using the same indicators for informal settlement detection in different geographical areas. This study investigates the performance of twelve image-based indicators on the detection of informal from formal settlements in Mamelodi, in South Africa, using WorldView 2 satellite imagery. In addition to commonly used informal settlement indicators, the study investigates two informal settlement indicators that can be derived from high-resolution satellite imagery.

\section{Study Area}

Mamelodi is one of the biggest townships in the city of Tshwane, South Africa, located $20 \mathrm{~km}$ east of the city, see Figure 1 . The total area of Mamelodi Township is around $32 \mathrm{~km}^{2}$. Mamelodi was established in 1953 as an urban housing scheme designed exclusively for 
occupation by black African residents. In line with Apartheid planning, Mamelodi was intended to provide a cheap labor pool for industries in Pretoria and the wider Gauteng region [28].

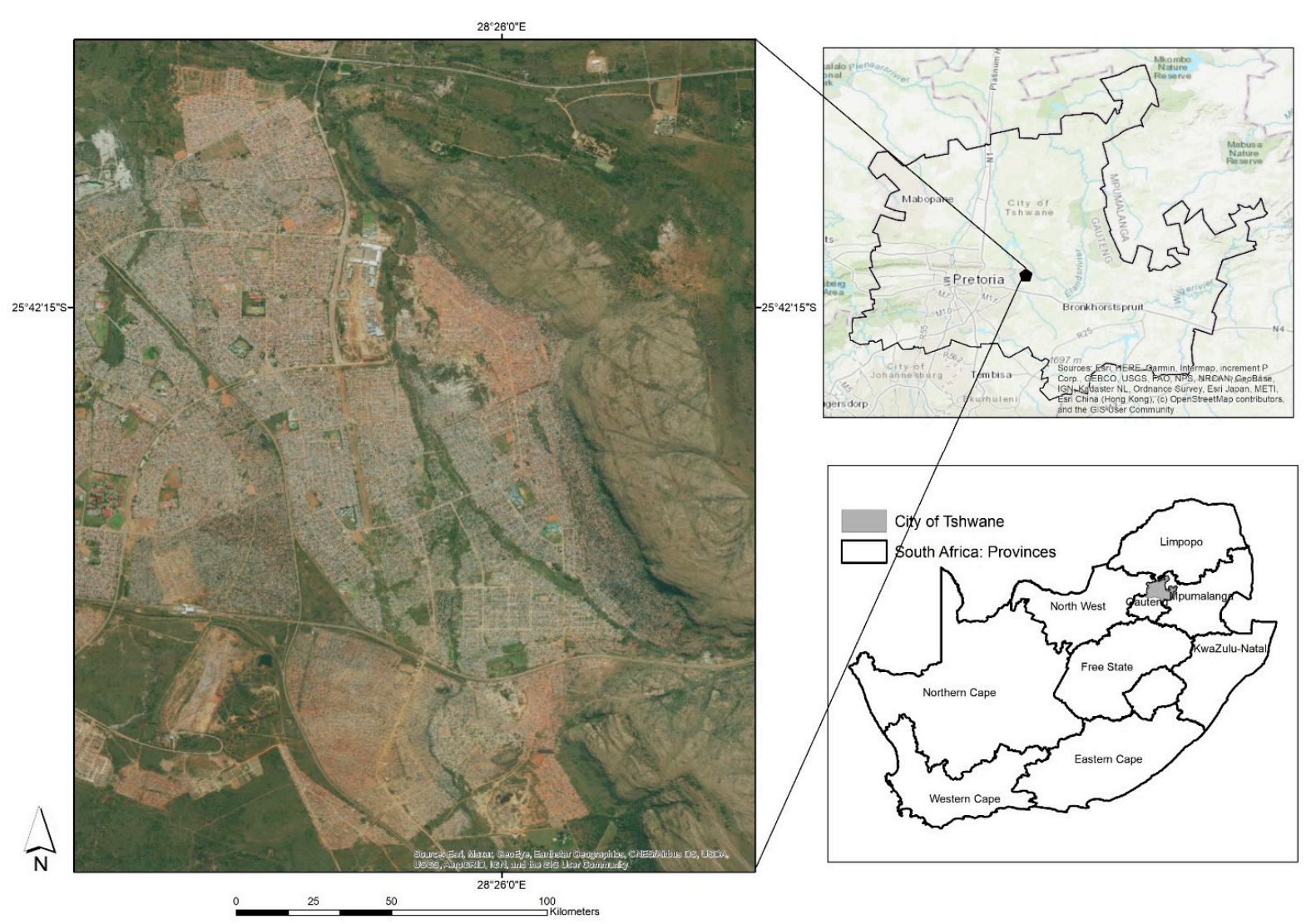

Figure 1. Location of the study areas.

Mamelodi Township has a population of 334,577 [29] and is home to many immigrants due to its connectivity to the Tshwane Central Business District. Consequently, this township is densely populated with large areas of informal settlements. About $50 \%$ of dwellings in Mamelodi were informal in 2011 [29]. Due to this high number of informal dwellings, the authorities are struggling to meet the housing demands and the provision of basic services. Additionally, Mamelodi is faced with many social and environmental challenges, including high crime rates, water pollution and solid waste management. In terms of the impact of informal settlements on the environment, the stream that flows through one informal settlement in Mamelodi is odorous and contaminated but still used for household chores putting the health of the people at risk [30]. Despite several informal settlement upgrade projects taking place in Mamelodi, the expansion of informal settlement is still on the rise. Spatial information on informal settlements is vital to ensure that local authorities and policymakers put necessary measures and resources aimed at upgrading informal settlements and managing their development.

\section{Data}

We used WorldView 2 8-band multispectral and panchromatic images acquired on 28 July 2015, sourced from Maxar Technologies. The multispectral bands and panchromatic bands have a spatial resolution of $2.4 \mathrm{~m}$ and $46 \mathrm{~cm}$, respectively. The 8 bands multispectral image contains coastal, blue, green, yellow, red, red edge near-infrared and near-infrared 2. The images were received georeferenced to the geographic coordinate system and WGS 84 data. The images covered Mamelodi East area, with the coordinates $25^{\circ} 41^{\prime}-25^{\circ} 45^{\prime} \mathrm{S}$ 
and $28^{\circ} 23^{\prime}-28^{\circ} 27^{\prime}$ E. Figure 2 shows an informal settlement in Mamelodi Township over WorldView 2 image.

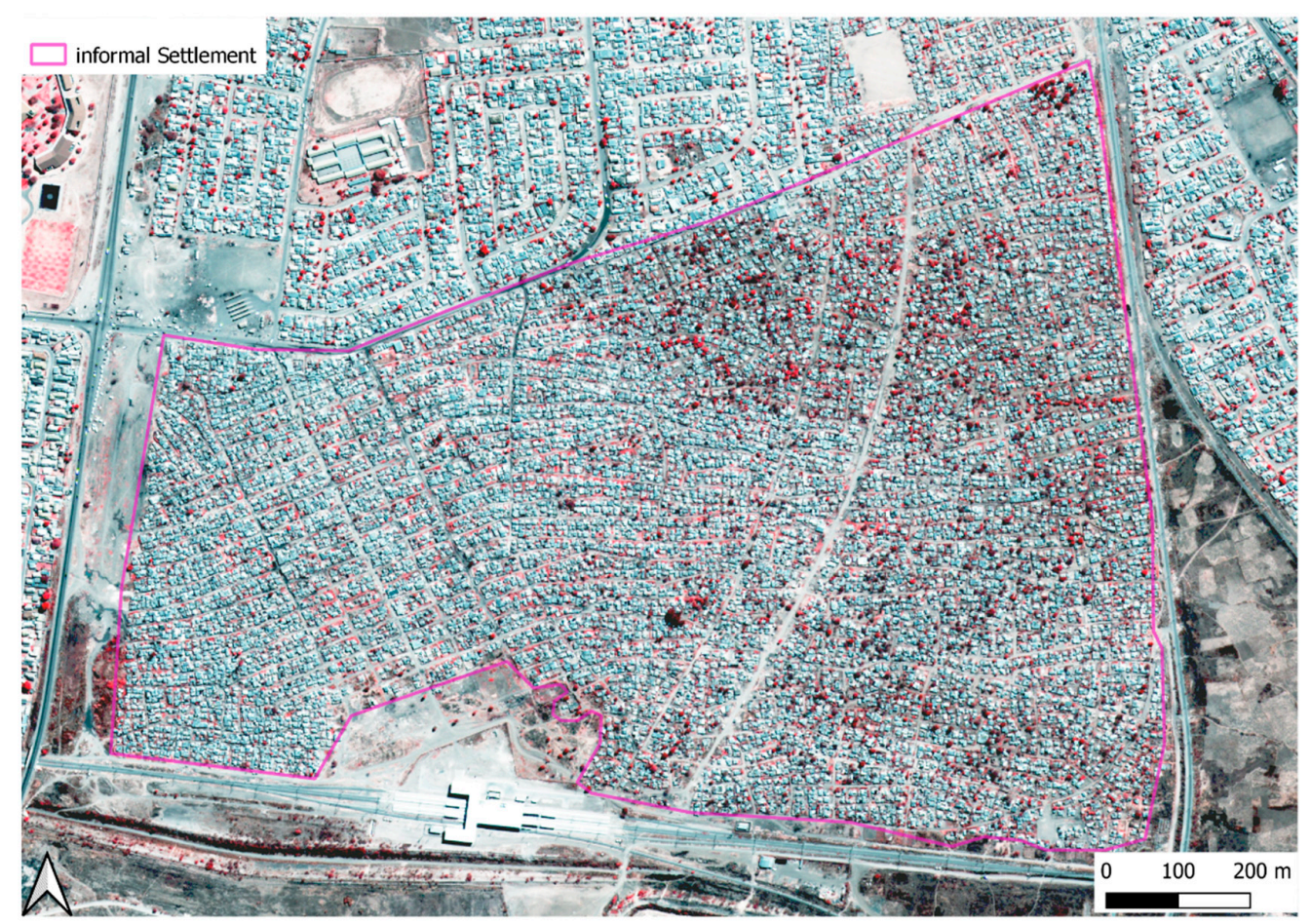

Figure 2. Extent of informal settlement over a Worldview 2 image.

\section{Method}

In this study, we used object-based image analysis (OBIA) to detect informal from formal settlements. The methodology followed involves segmentation of an image into smaller image tiles, selection of samples, assessment of informal settlement indicators, built-up and non-built-up classification, detection of informal settlements and accuracy assessment, Figure 3. The processing was done using Trimble eCognition Developer 9 software. Sections 4.1-4.4 explain the processes followed.

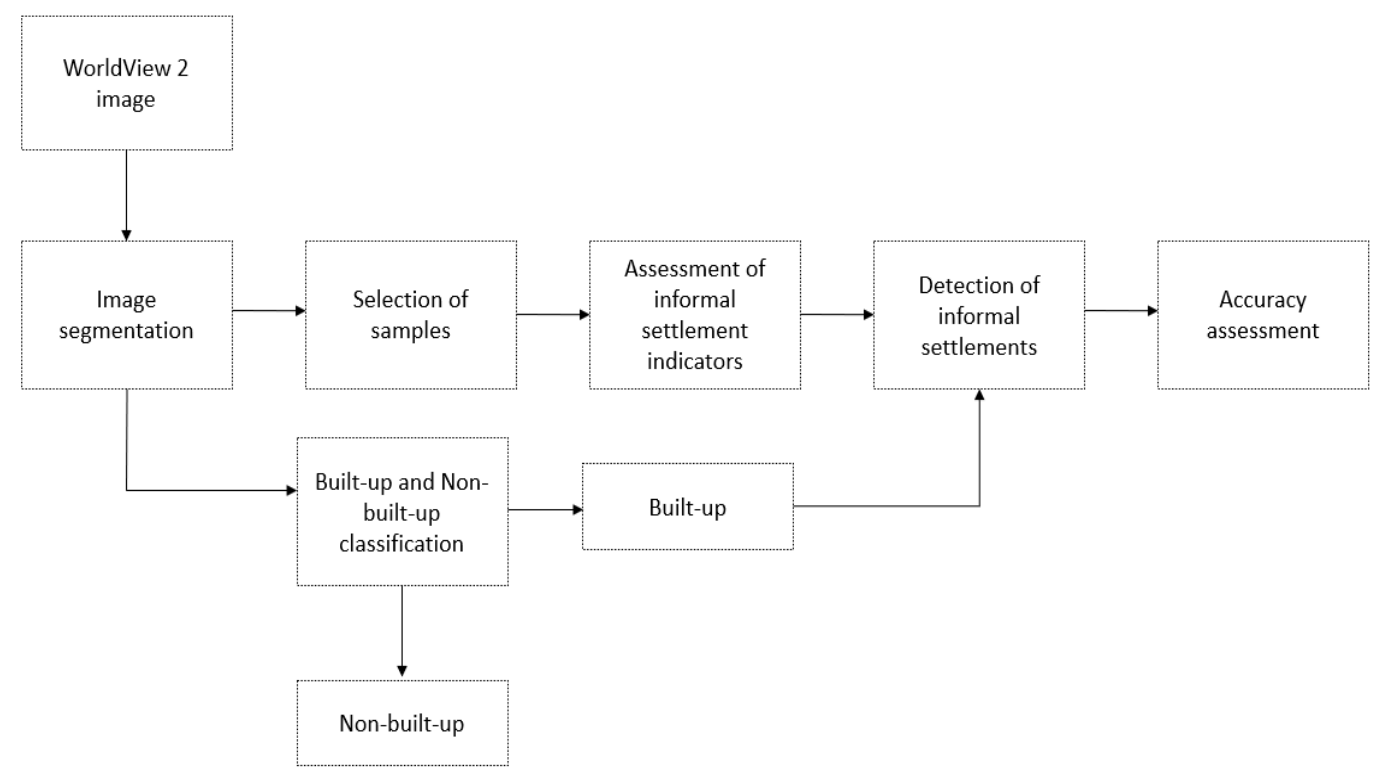

Figure 3. Methodology followed to detect informal settlements. 


\subsection{Image Segmentation}

The most important step in OBIA classification is image segmentation, which partitions an image into desired objects, which are used during image classification or image interpretation. In this study, a grid-based segmentation was chosen to allow for the assessment and classification of formal and informal settlements based on the characteristics and patterns of the land-use features within a grid. We used the chessboard segmentation techniques to segment the image into 150 by 150 pixels tiles or grids. Chessboard image segmentation algorithm partitions an image into smaller square objects [31]. This segmentation algorithm uses only the scale parameter and does not consider the spectral or shape features of the objects [32]. The selection of the tile size was done using an interactive approach based on expert knowledge of the study area.

\subsection{Assessment of Informal Settlement Indicators}

Table 1 lists the informal settlement indicators that were assessed and image-based indicators investigated.

Table 1. List of informal settlement indicators investigated in the classification of informal from formal settlements.

\begin{tabular}{|c|c|c|}
\hline Informal Settlement Indicator & Image-Based Indicator & Formula \\
\hline Vegetation cover & Normalized difference vegetation index (NDVI) & NIR $-\mathrm{R} / \mathrm{NIR}+\mathrm{R}$ \\
\hline Built-up area & Built-up area index (BAI) & $\mathrm{B}-\mathrm{NIR} / \mathrm{B}+\mathrm{NIR}$ \\
\hline Iron cover & Iron index & $\mathrm{B} / \mathrm{G}$ \\
\hline Asphalt cover & Road extraction index (REI) & $\mathrm{NIR} 2-\mathrm{B} / \mathrm{NIR} 2+\mathrm{B} * \mathrm{NIR} 2$ \\
\hline Built-up area & Coastal blue index & $\mathrm{C}-\mathrm{NIR} / \mathrm{C}+\mathrm{NIR}$ \\
\hline \multicolumn{3}{|l|}{ Texture } \\
\hline & Gray level co-occurrence matrix (GLCM) mean & $\sum_{i, j=0}^{n-1} i\left(P_{i, j}\right)$ \\
\hline & GLCM variance & $\sum_{i, j=0}^{n} P_{i, j}(i j)^{2}$ \\
\hline & GLCM homogeneity & $\sum_{i, j=0}^{n} \sum_{i, j=0}^{n} \frac{P_{i, j}}{1+(i-j)^{2}}$ \\
\hline & GLCM contrast & $\sum_{i, j=0}^{n-1} P_{i, j}(i-j)^{2}$ \\
\hline & First-order statistics (FOS) mean $(\mathrm{u})$ & $\frac{1}{n} \sum_{i,=0}^{n-1}\left(P_{i}\right)$ \\
\hline & FOS variance & $\frac{1}{n} \sum_{i,=0}^{n-1} P(i)(i-u)^{2}$ \\
\hline & FOS skewness & $\frac{1}{n} \sum_{i,=0}^{n-1} P(i)(i-u)^{3}$ \\
\hline
\end{tabular}

Where NIR, R, B, G and C are Near-infrared, Red, Blue, Green and Coastal Blue bands respectively, $n$ is the total number of gray levels in the image; The matrix element $P(i, j)$ is the set of second-order statistical probability values for changes between gray level $i$ and $j$ at a particular displacement distance and $P_{i}$ is the probability of each pixel.

The indicators assessed included the commonly investigated informal settlement indicators, which are vegetation cover, asphalt cover and texture [8]. In addition, we assessed the performance of the built-up area and iron cover in distinguishing between informal and formal settlements.

The density of building structures in the informal settlements varies across the study area from 5 to more than 15 building structures per $100 \mathrm{~m}^{2}$. Lack of vegetation or limited vegetation has been used as an indication of informal settlements [23]. Several studies have concluded that vegetation cover in informal settlements is lower than in low-density formal settlements $[15,23,27]$. We used vegetation cover derived using normalized difference vegetation index (NDVI) to investigate its performance in the detection of informal settlements.

Built-up area indices have been used to highlight built-up areas from other land cover features from satellite imagery [33-35]. Areas with high built-up density have higher built-up index values compared to areas with lower density built-up areas. We used the 
built-up area index (BAI) [36] to assess the separation of formal and informal settlements. In addition to BAI, we developed a new built-up index, which is based on the coastal band, i.e., coastal blue index and assessed the separability of the two settlement types.

Absence or irregular roads have been identified as an indicator of informal settlements [8]. We used the road extract index (REI) [37] to investigate the separation of informal and formal settlements. The REI highlights asphalt surfaces from other land-use features. The road surfaces or paths in informal settlements in the study area are not paved.

In addition to the commonly used spectral indicators, we investigated the effectiveness of the iron index in separating informal from formal settlements. The roofs of building structures in informal settlements in the study area contain various materials, such as corrugated iron, woods, stones, and/or cloth sheets. The formal settlements contain roofs with iron oxide roof tiles or iron sheets and are, therefore, expected to have higher values of the iron index.

Texture is one of the most important spatial characteristics used in identifying the object of regions of interest [38]. Gray level co-occurrence matrix (GLCM) is a secondorder statistic measure and one of the commonly used methods in urban mapping. GLCM measures the spatial relations of neighboring pixels and is one of the investigated texture analysis methods in informal settlements detection. The GLCM textural measures have been used towards slum or informal settlements detection with varying accuracy from one area to the other due to the morphology of informal settlements [25-27,39]. We have assessed the performance of GLCM mean, variance, contrast and homogeneity textural features in separating informal from formal settlements.

Lastly, we assessed the performance of first-order statistics (FOS) measurement, mean, variance and skewness in distinguishing informal from formal settlements. These measurements calculate statistics based on the individual pixels and do not take into account the relationship to the neighboring pixels $[40,41]$. The informal settlements are illegal in nature, leading to an organic pattern of dwelling pattern and irregular or lack of road networks and other land use activities. Consequently, the texture measures between formal and informal settlements vary [39]. We used feature space optimization (FSO) to determine the separability of 72 and 78 informal and formal sample objects against all the twelve image-based indicators listed in Table 1. The samples were selected using visual image interpretation and contained settlements with varying dwelling structure density and vegetation cover. Image tiles created during the segmentation process, which contained formal or informal settlements, were selected as samples. The FSO is an eCognition software tool that evaluates the Euclidean distance in feature space between sample objects to determine the best separation distance [42].

\subsection{Detection of Informal Settlements}

The first step in the detection of informal settlements was to separate built-up from non-built-up areas. We used GLCM dissimilarity textural analysis to classify built-up from non-built-up objects. The GLCM dissimilarity textural analysis separates built-up from non-built-up areas with higher accuracy than other GLCM textural features and spectral indices [33].

The classification of informal from formal settlements was applied on the built-up class using indicators and image-based indicators that produced high informal settlement class separation as explained in 4.2. The ruleset to detect informal settlement was developed using FOS mean, BAI and coastal blue index and thresholding technique. The thresholds were determined by visually inspecting informal and formal objects.

Table 2 lists the values of the image-based indicators used in the detection of informal settlements.

\subsection{Accuracy Assessment}

Accuracy assessment was done by comparing informal and formal sample objects created in Section 4.2 and the classified informal settlement objects using a confusion matrix. 
Table 2. Image-based indicators and values used to classify informal and formal settlements.

\begin{tabular}{cc}
\hline Image-Based Indicators & Class Threshold \\
\hline GLCM dissimilarity & $\begin{array}{c}\text { Non-built-up }<0.8 \\
\text { Built-up }>0.8\end{array}$ \\
\hline FOS mean & $\begin{array}{c}\text { Formal settlements }>550 \\
\text { Informal settlements }<550\end{array}$ \\
\hline BAI & $\begin{array}{c}\text { Formal settlements }>550 \\
\text { Informal settlements }<550\end{array}$ \\
\hline Coastal blue & $\begin{array}{c}\text { Formal settlement }>500 \\
\text { Informal settlements }>500\end{array}$ \\
\hline
\end{tabular}

\section{Results}

\subsection{Image Segmentation}

The chessboard segmentation method was able to create formal settlements, informal settlements and non-built-up objects. Open spaces, such as sports fields and parks within the built-up area, were separated from other land-use features, Figure 4. There were, however, tiles that contained parts of open areas and a small portion of settlements. In addition, there were few areas where both formal and informal settlements formed part of one tile. This was observed mostly in the edges of informal and formal settlements.

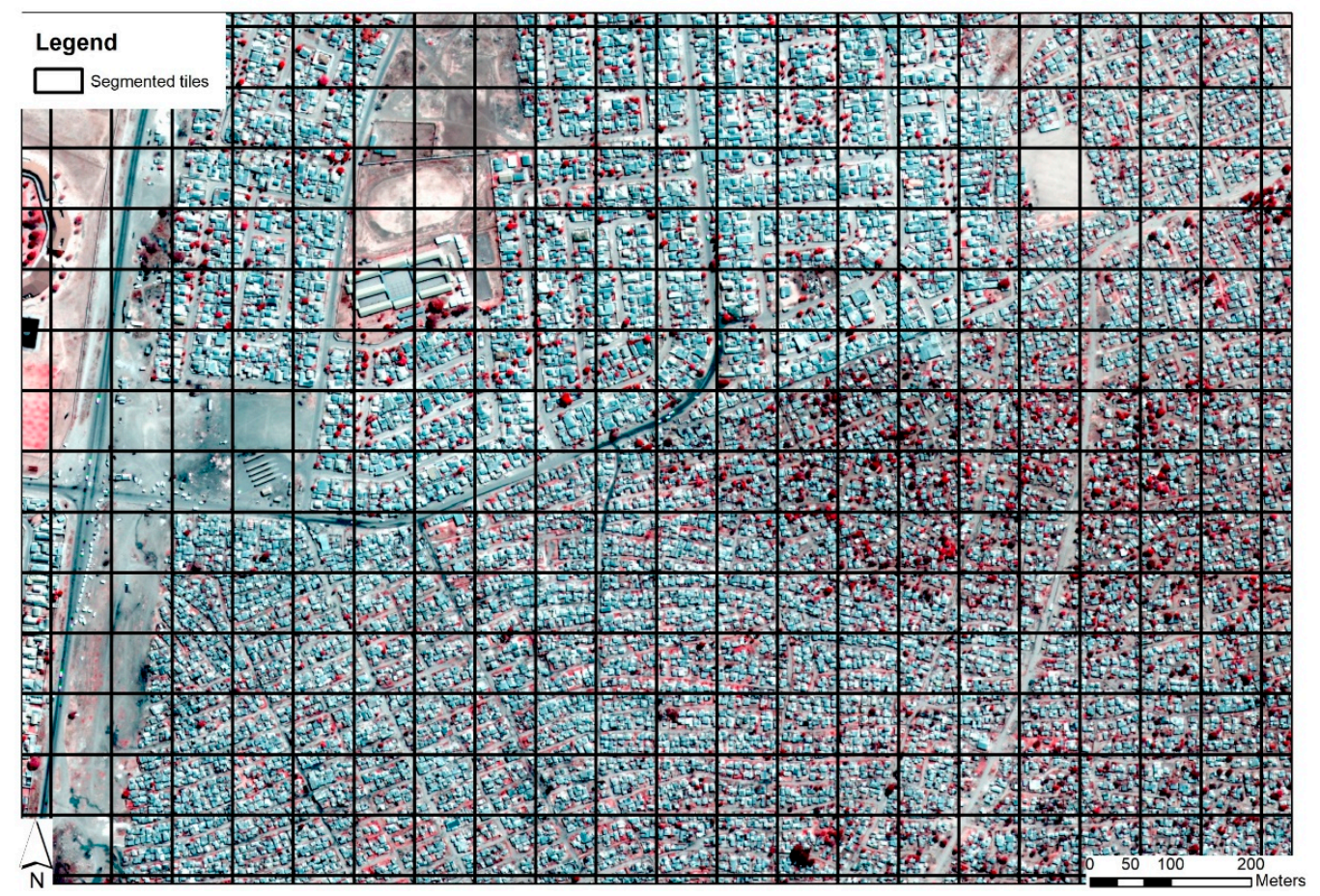

Figure 4. Segmentation results over WorldView 2 image.

\subsection{Performance of Selected Image-Based Indicators in Separating Informal and Formal Settlements}

The FSO class separability results are shown in Table 3. The results show that the GLCM mean, variance, homogeneity and contrast, produced the lowest class separation distance of informal and formal settlements compared to spectral indices and FOS measurements. The GLCM variance, homogeneity and contrast had the best separating distance of the two classes of less than 0.02, with GLCM contrast having the least separation distance of 0.001 . The results indicate that the selected GLCM textural measures are not effective in distinguishing informal from formal settlements in a densely populated area. This can be attributed to the varying densities of building structures and other land-use features 
in informal settlements resulting in varying co-occurrence values within the informal settlements class.

Table 3. Performance of selected image-based indicators in classifying informal from formal settlements.

\begin{tabular}{cc}
\hline Image-Based Indicator & Separability \\
\hline Normalized difference vegetation index & 0.075 \\
Built-up area index & 0.201 \\
Iron index & 0.191 \\
Road extraction index & 0.036 \\
Coastal blue band & 0.219 \\
GLCM mean & 0.100 \\
GLCM variance & 0.019 \\
GLCM homogeneity & 0.001 \\
GLCM contrast & 0.011 \\
FOS mean & 0.235 \\
FOS variance & 0.019 \\
FOS skewness & 0.027 \\
\hline
\end{tabular}

The separation of informal and formal classes using NDVI and REI yielded the least separability distances of 0.075 and 0.036 , respectively, compared to other spectral indices. The poor performance of NDVI can be attributed to the fact that the informal settlements in the study area vary in vegetation cover and density. Low vegetation cover was observed in high-density informal settlements, whereas some of the lower-density informal settlements had higher vegetation cover than some of the formal settlements. The lower separation distance of the two classes using REI can be attributed to similar spectral properties of road and building structures in the study area. In addition, unpaved roads can be observed in both formal and formal settlements adding the confusion between the two classes.

The coastal blue index and BAI resulted in a better separability between informal and formal settlements with the best separation distances of 0.219 and 0.201 , respectively, compared to other spectral indices. Most of the informal settlement tiles have lower builtup index values compared to formal areas. The use of the coastal blue index slightly increased the separability of the two classes compared to BAI. The coastal blue index was able to separate some of the dense informal settlements from formal areas that have similar values when using BAI.

The iron index performed better than NDVI and REI, with the best separation distance of 0.191 between the two classes. The informal settlements have lower values of the iron index compared to formal areas. This is due to the diversity of roof material found in informal settlements, whereas the roofs in formal settlements contain a mixture of iron sheets or iron oxide tiles, resulting in higher iron index values. The iron index failed to detect high-density informal settlements and resulted in an increased confusion between low-density informal and formal areas.

The FOS mean produced the highest separability distance of 0.235 compared to all image-based indicators investigated, whereas FOS skewness and FOS variance performed slightly better than the GLCM variance, homogeneity and contrast. The FOS mean was effective in detecting low-density informal settlements with lower spectral values but failed to detect high-density informal settlements.

\subsection{Informal and Formal Settlements Classification Results}

This section presents the classification results of built-up and non-built-up classes, informal and formal settlements, and accuracy assessment results achieved on the classification of informal settlements using the top three image-based indicators, which, i.e., FOS mean, coastal blue index and BAI.

The GLCM dissimilarity was successful in classifying built-up and non-built-up areas. Some of the image tiles with more than $50 \%$ non-built-up were classified as non-built-up. These areas were found mostly in the edges of the settlements. 
The use of the FOS, coastal blue index and BAI were successful in classifying informal from formal settlements, Figure 5. Most of the informal settlements in the study have lower values of the built-up index than formal settlements. This is due to a lower amount of impervious surface in informal settlements in the study area. Hence they were detectable using BAI and the coastal blue index. Some of the lower-density informal settlements also have lower values of FOS mean compared to formal settlements. The FOS mean and BAI are unable to separate high-density informal settlements from formal areas. These areas have a higher amount of impervious surface and high mean values compared to low-density informal settlements. The detection of high-density informal settlements was slightly improved by the coastal blue index though at the same time introducing commission errors in some of the high-density formal settlements tiles. Some of the tiles representing formal settlements that are on the edges of settlements were also misclassified due to the contribution of spectral properties of open spaces, which are similar to some of the informal settlement tiles.

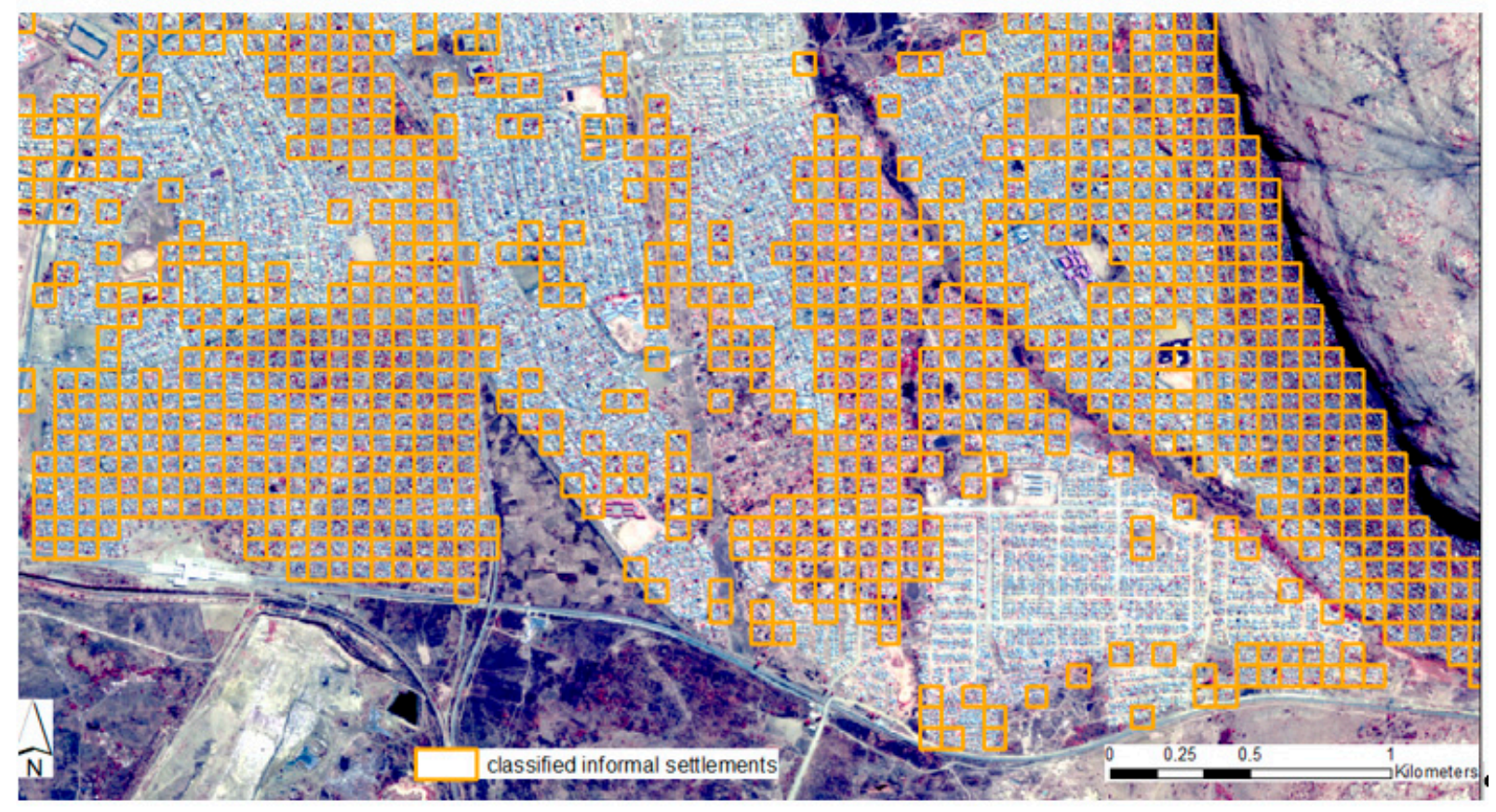

Figure 5. Detected informal settlement layer over Worldview 2 image.

Assessment top three image-based indicators used separately show that BAI produced the highest overall accuracy of $90 \%$, followed by coastal blue index with $88 \%$. The coastal blue index produced the highest producer accuracy of informal settlements of $94 \%$, followed by BAI with $84 \%$, while the FOS mean yielded producer accuracy of $80 \%$. The use of FOS mean and BAI resulted in an overall accuracy of $90 \%$ and a producer accuracy of informal settlements of $87 \%$. The use of BAI and coastal blue index in the ruleset produced an overall accuracy of $88 \%$ and producer accuracy of informal settlements of $95 \%$. The inclusion of the coastal blue index with BAI and FOS in the ruleset increased the overall accuracy by $1 \%$ and the producer accuracy of informal settlements by $6 \%$. In addition, the use of coastal blue index with FOS mean and BAI in the detection of informal settlements increased the kappa index Agreement of informal settlements from $75 \%$ to $87 \%$ but reduced the kappa index Agreement of formal settlements from $88 \%$ and $69 \%$. This shows that the coastal blue index increased the amount of correctly classified informal settlement tiles but also increased the confusion between informal and formal settlements.

The areas detected by FOS mean overlap with the areas detected by BAI and coastal blue index, whereas the built-up indices can detect additional informal settlements with higher FSO mean values. This shows that the proposed methodology depends highly on 
the built-up indices. BAI may be applied on very high spatial resolution images that do not have a coastal blue band, whereas the coastal blue index can be applied in images with the coastal blue band.

\section{Conclusions}

Our study showed the importance of studying the characteristics of informal settlements in different geographic areas to develop methodologies to automatically detect informal settlements. In this study, we investigated the performance of twelve informal settlement indicators in classifying informal from formal settlements. Using the FSO class separation assessment tool, only three out of twelve indicators had the best separation distance of informal and formal settlements of more than 0.2. These indicators are the FOS mean and built-up indices, i.e., BAI and coastal blue index. The study successfully identified and demonstrated a built-up area as an informal settlement indicator and a built-up index derived using the coastal band. The study also identified iron cover as an informal settlement indicator that can improve the detection of informal settlements. The study showed that the GLCM measurements performed poorly in distinguishing informal and formal settlements in the study area. The FOS variance and skewness were not successful in distinguishing between informal and formal settlements. The study also showed that vegetation cover was not effective in detecting informal settlements. This contradicts many studies that suggested that informal settlements have lower vegetation cover than formal areas. Asphalt cover derived using REI was also not effective in detecting informal settlements in the study area.

The study results contributed additional informal settlement indicators and imagebased indicators that can be tested in certain areas and contribute to developing tools to detect informal settlements. Even though higher accurate results were achieved in the study, the proposed methodology needs to be tested in other areas with informal settlements of similar characteristics. In addition, there is a need to performs a thorough assessment of the twelve indicators using class separability tools with higher accuracy, such as Jeffries Matusita distance, to assess the limitation and opportunities of the indicators investigated. The performance of these indicators can also be tested using the multiresolution segmentation method. Lastly, there is a need to investigate the informal settlement indicators that distinguish high-density informal settlements from high-density formal settlements with backyard shacks using very high spatial resolution imagery acquired by drone or aerial photography.

Author Contributions: Conceptualization, N.M.; investigation, N.M.; methodology, N.M.; supervision, P.M.; writing—original draft, N.M.; writing—review and editing, N.M. All authors have read and agreed to the published version of the manuscript.

Funding: This research received no external funding.

Institutional Review Board Statement: Not Applicable.

Informed Consent Statement: Not Applicable.

Data Availability Statement: The results reported in this paper can be accessed for non-commercial purposes by contacting the authors.

Conflicts of Interest: The authors declare no conflict of interest.

\section{References}

1. United Nations. World Urbanization Prospects 2018; United Nations: New York, NY, USA, 2019.

2. Kessides, C. The urban transition in sub-Saharan Africa: Challenges and opportunities. Environ. Plan. C Gov. Policy 2007, 24, 466-485. [CrossRef]

3. UN-Habitat. The Challenges of Slums: Global Report on Human Settlements; UN-Habitat: Nairobi, Kenya, 2003.

4. UN-Habitat. UN-Habitat Strategic Vision; UN-Habitat: Nairobi, Kenya, 2003.

5. Patel, S.; Baptist, C. Documenting by the undocumented. Environ. Urban. 2012, 12, 3-12. [CrossRef] 
6. Kakembo, V.; van Niekerk, S. The integration of GIS into demographic surveying of informal settlements: The case of Nelson Mandela Bay Municipality, South Africa. Habitat Int. 2014, 44, 451-460. [CrossRef]

7. Kohli, D.; Stein, A.; Sliuzas, R. Uncertainty analysis of image interpretation of urban slums. Comput. Environ. Urban Syst. 2016, 60, 37-49. [CrossRef]

8. Kohli, D.; Sliuzas, R.; Kerle, N.; Stein, A. An ontology of slums for image-based classification. Comput. Environ. Urban Syst. 2012, 36, 154-163. [CrossRef]

9. The Housing Development Agency. South Africa: Informal Settlements Status. 2012. Available online: http://www.thehda.co. za/uploads / files/HDA_Informal_settlements_status_South_Africa.pdf (accessed on 4 August 2020).

10. United Nations Population Fund. Population and Housing Census: Strategies for Reducing Costs. 2002. Available online: https:/ /www.unfpa.org/sites/default/files/pub-pdf/population_census.pdf (accessed on 4 August 2020).

11. Patino, E.; Duque, J. A review of regional science applications of satellite remote sensing in urban settings. Comput. Environ. Urban Syst. 2013, 37, 1-17. [CrossRef]

12. Li, J.; Li, Y.; Chapman, M.A.; Rüther, H. Small Format Digital Imaging for Informal Settlement Mapping. Photogramm. Eng. Remote Sens. 2013, 71, 435-442. [CrossRef]

13. Williams, N.; Quincey, D.; Stillwell, J. Automatic Classification of Roof Objects from Aerial Imagery of Informal Settlements in Johannesburg. Appl. Spat. Anal. Policy 2005, 9, 269-281. [CrossRef]

14. Gevaert, C.; Persello, C.; Sliuzas, R.; Vosselman, G. Classification of informal settlements through the integration of 2D and 3D features extracted from UAV data. In Proceedings of the XXIII ISPRS Congress, Prague, Czech Republic, 12-19 July 2016.

15. Hofmann, P. Detecting informal settlements from Ikonos image data using methods of object oriented image analysis-An example from Cape Town (South Africa). In Remote Sensing of Urban Areas; Jürgens, C., Ed.; Regensburger Geographische Schriften: Regensburg, Germany, 2001.

16. Hofmann, P.; Strobl, J.; Blaschke, T.; Kux, H. Detecting Informal Settlements from Quickbird Data in Rio de Janeiro Using an Object Based Approach. In Object Based Image Analysis: Spatial Concept for Knowledge-Driven Remote Sensing; Blaschke, T., Lang, S., Hay, G.J., Eds.; Springer: Heidelberg/Berlin, Germany, 2008; pp. 531-553.

17. Ribeiro, B.M.G. Mapping informal settlements using WorldView-2 imagery and C4.5 decision tree classifier. In Proceedings of the 2015 Joint Urban Remote Sensing Event (JURSE), Lausanne, Switzerland, 30 March-1 April 2015.

18. Kuffer, M.; Barros, J. Urban Morphology of Unplanned Settlements: The Use of Spatial Metrics in VHR Remotely Sensed Images. Comput. Environ. Urban Syst. 2014, 48, 138-152. [CrossRef]

19. Jain, S. Use of IKONOS satellite data to identify informal settlements in Dehradun, India. Int. J. Remote Sens. 2007, 28, 3227-3233. [CrossRef]

20. Kuffer, M.; Pfeffer, K.; Sliuzas, R. Slums from Space-15 Years of Slum Mapping Using Remote Sensing. Remote Sens. 2016, 8, 455. [CrossRef]

21. Kohli, D.; Warwadekar, P.; Kerle, N.; Sliuzas, R.; Stein, A. Transferability of object-oriented image analysis methods for slum identification. Remote Sens. 2013, 5, 4209-4228. [CrossRef]

22. Pesaresi, M.; Ehrlich, D. A methodology to quantify built-up structures from optical VHR imagery. In Global Mapping of Human Settlement; Gamba, P., Herold, M., Eds.; CRC Press: Boca Raton, FL, USA, 2009; pp. 531-553.

23. Owen, K.K.; Wong, D.W. An approach to differentiate informal settlements using spectral, texture, geomorphology and road accessibility metrics. Appl. Geogr. 2013, 38, 107-118. [CrossRef]

24. Sliuzas, R.; MBoup, G.; Sherbinin, A. Report of the Expert Group Meeting on Slum Identification and Mapping; ITC: Enschede, The Netherlands, 2008.

25. Kuffer, M.; Pfeffer, K.; Sliuzas, R.; Baud, I.I. Extraction of Slum Areas from VHR Imagery Using GLCM Variance. IEEE J. Sel. Top. Appl. Earth Obs. Remote Sens. 2016, 9, 1830-1840. [CrossRef]

26. Prabhu, R.; Alagu Raja, R.A. Urban Slum Detection Approaches from High-Resolution Satellite Data Using Statistical and Spectral Based Approaches. J. Indian Soc. Remote Sens. 2018, 46, 2033-2044. [CrossRef]

27. Fallatah, A.; Jones, S.M.D.; Kohli, D. Mapping informal settlement indicators using object-oriented analysis in the Middle East. Int. J. Digit. Earth 2018, 12, 802-824. [CrossRef]

28. South African Cities Network. The State of South African Cities; South Africa Cities Network: Johannesburg, South Africa, 2011.

29. Statistics South Africa. Census 2011. 2013. Available online: http:/ /www.statssa.gov.za/census/census_2011/census_products/ Census_2011_Fact_sheet.pdf (accessed on 30 October 2020).

30. Darkey, D.; Donaldson, S.E. Water pollution and community perceptions in Mamelodi, Pretoria. In Proceedings of the WISA 2000 Biennial Conference, Sun City, South Africa, 28 May-1 June 2000.

31. Liu, J.; Chen, Z.; Gao, J.; Gao, X.; Sun, Z. The method of determining the optimal segmentation scale for high-resolution image tree species classification. For. Sci. 2019, 55, 95-104.

32. Xue, B.; Lin, X. Water System Segmentation Method of High Resolution Remote Sensing Image Based on eCognition. J. Phys. Conf. Ser. 2020, 1651, 012162. [CrossRef]

33. Zhang, J.; Li, P.; Wang, J. Urban Built-Up Area Extraction from Landsat TM/ETM+ Images Using Spectral Information and Multivariate Texture. Remote Sens. 2014, 6, 7339-7359. [CrossRef]

34. He, C.; Shi, P.; Xie, D.; Zhao, Y. Improving the normalized difference built-up index to map urban built-up areas using a semiautomation segmentation approach. Remote Sens. Lett. 2010, 1, 213-221. [CrossRef] 
35. Bhatti, S.S.; Tripathi, N.K. Built-up Area Extraction Using Landsat 8 OLI Imagery. GISci. Remote Sens. 2014, 51, 445-467. [CrossRef]

36. Mhangara, P.; Odindi, J.; Kleyn, L.; Remas, H. Road Extraction Using Object Oriented Classification. Available online: https: //www.ee.co.za/wp-content/uploads/legacy/posit11/PositionIT_nov-dec11-Vis_45-50.pdf (accessed on 15 September 2020).

37. Shahi, K.; Shafri, H.Z.; Taherzadeh, E.; Mansor, S.; Muniandy, R. A novel spectral index to automatically extract road networks fromWorldView-2 satellite imagery. Egypt. J. Remote Sens. Space Sci. 2015, 18, 27-33.

38. Haralick, R.; Shanmugam, K.; Dinstein, I. Textural features for Image Classification. IEEE Trans. Syst. Man Cybern. 1973, 6, 610-621. [CrossRef]

39. Ansari, R.A.; Buddhiraju, K.M. Textural segmentation of remotely sensed images using multiresolution analysis for slum area identification. Eur. J. Remote Sens. 2019, 52, 74-88. [CrossRef]

40. Kumar, V.; Gupta, P. Importance of Statistical Measures in Digital Image Processing. Int. J. Emerg. Technol. Adv. Eng. 2012, 2, $56-62$.

41. Namita Aggarwal, R.K. Agrawal, First and Second Order Statistics Features for Classification of Magnetic Resonance Brain Images. J. Signal Inf. Process. 2012, 3, 146-153.

42. Van Ho, T.; Rao, P.J. Feature Selection Methods for Object Based Classification of Tropical Forest Using Spot 5 Imagery. J. Remote Sens. GIS 2016, 7, 41-49. 